\title{
MRI Correlates of Protein Deposition and Disease Severity in Postmortem Frontotemporal Lobar Degeneration
}

\author{
Jennifer L. Whitwell ${ }^{a} \quad$ Clifford R. Jack, Jr. ${ }^{a} \quad$ Matthew L. Senjem ${ }^{b}$ \\ Joseph E. Parisic Bradley F. Boeve ${ }^{d}$ David S. Knopman ${ }^{d}$ Dennis W. Dickson ${ }^{e}$ \\ Ronald C. Petersen ${ }^{d}$ Keith A. Josephs ${ }^{d}$ \\ Departments of a Radiology, ${ }^{\mathrm{b}}$ Information Technology, ${ }^{\mathrm{C}}$ Laboratory Medicine and Pathology, and \\ ${ }^{\mathrm{d} N e u r o l o g y}$, Mayo Clinic Rochester, Rochester, Minn., and e Department of Neuroscience and Neuropathology, \\ Mayo Clinic Jacksonville, Jacksonville, Fla., USA
}

\section{Key Words}

Frontotemporal lobar degeneration - Autopsy $\cdot$ Tau •

TAR DNA binding protein-43 $\cdot$ Voxel-based morphometry •

Clinical Dementia Rating Scale $\cdot$ Mini-Mental State

Examination

\begin{abstract}
Background: Frontotemporal lobar degeneration (FTLD) can be classified based on the presence of the microtubuleassociated protein tau and the TAR DNA binding protein-43 (TDP-43). Future treatments will likely target these proteins, therefore it is important to identify biomarkers to help predict protein biochemistry. Objective: To determine whether there is an MRI signature pattern of tau or TDP-43 using a large cohort of FTLD subjects and to investigate how patterns of atrophy change according to disease severity using a large autopsy-confirmed cohort of FTLD subjects. Methods: Patterns of gray matter loss were assessed using voxelbased morphometry in 37 tau-positive and 44 TDP-43-positive subjects compared to 35 age and gender-matched controls, and compared to each other. Comparisons were also repeated in behavioral variant frontotemporal dementia (bvFTD) subjects ( $n=15$ tau-positive and $n=30$ TDP-43positive). Patterns of atrophy were also assessed according
\end{abstract}

\section{KARGER}

๑ 2009 S. Karger AG, Basel

Fax +4161306 1234 E-Mail karger@karger.ch www.karger.com to performance on the Clinical Dementia Rating (CDR) scale and Mini-Mental State Examination (MMSE). Results: The tau-positive and TDP-43-positive groups showed patterns of frontotemporal gray matter loss compared to controls with no differences observed between the groups, for all subjects and for bvFTD subjects. Patterns of gray matter loss increased in a graded manner by CDR and MMSE with loss in the frontal lobes, insula and hippocampus in mild subjects, spreading to the temporal and parietal cortices and striatum in more advanced disease. Conclusion: There is no signature pattern of atrophy for tau or TDP-43; however, patterns of atrophy in FTLD progress with measures of clinical disease severity.

Copyright $\odot 2009$ S. Karger AG, Basel

\section{Introduction}

Frontotemporal lobar degeneration (FTLD) is a heterogeneous disorder that consists of a number of different pathological variants. These variants can be classified based on the presence of the microtubule-associated protein tau (MAPT) [1], TAR DNA binding protein-43 (TDP43) $[2,3]$, and those which do not fit into either category [3]. Variants that are defined by the presence of tau (tau- 
positive) include Pick's disease (PiD), corticobasal degeneration (CBD), progressive supranuclear palsy (PSP), sporadic multiple system tauopathy (MST) and FTLD with mutations in the MAPT gene (FTLD-tau). The most common variants that are TDP-43-positive include FTLD with ubiquitin-immunoreactive inclusions either with (FTLD-MND) or without (FTLD-U) the presence of motor neuron degeneration [4]. It is likely that future treatments will target these specific proteins and therefore it is increasingly important to be able to predict the protein biochemistry during life. The clinical syndromes that can result from these proteinopathies are heterogenous [5-8] and hence there is a need for other biomarkers of protein deposition.

Patterns of atrophy on magnetic resonance imaging (MRI) have been shown to vary according to pathological diagnosis in FTLD [9-11], although it is still uncertain whether a signature of tau or TDP-43 exists that could help in prediction of the underlying protein. The aim of this study was therefore to assess patterns of atrophy across large cohorts of tau-positive and TDP-43-positive FTLD to determine whether there is an imaging signature of tau or TDP-43. Furthermore, tau-positive and TDP-43-positive pathologies will be compared in a homogenous clinical cohort of subjects by limiting the analysis only to those subjects with behavioral variant frontotemporal dementia (bvFTD) to determine whether imaging can help predict pathology for a single clinical phenotype, i.e. in the most common clinical variant [12]. In addition, in order for imaging to be useful as a biomarker it is also important to understand the relationship between the patterns of atrophy and the commonly used measures of disease severity. While numerous studies have investigated the relationship between atrophy and cognitive performance in subjects with AD [13-19], very little is known about the correlation in FTLD subjects. Therefore, we also aimed to investigate patterns of atrophy according to disease stage, by subdividing the pathologically confirmed subjects according to performance on both functional and cognitive testing.

\section{Methods}

\section{Subject Selection}

A total of 81 autopsy-confirmed subjects were identified from the neuropathology files of the Mayo Clinic, Rochester, Minn., USA which had come to autopsy and had a pathological diagnosis of FTLD and that had a volumetric MRI scan. These patients were all seen by a Behavioral Neurologist within the Department of Neurology, Mayo Clinic. Of these subjects, 37 had a tau-positive disease $(\mathrm{CBD}=12, \mathrm{PSP}=14, \mathrm{PiD}=4, \mathrm{MST}=2, \mathrm{FTLD}$-tau $=5)$ and 44 had a TDP-43-positive disease (FTLD-U = 33, FTLD$\mathrm{MND}=11$ ). The pathological criteria used to define these groups are outlined below. Imaging results have been previously published on some of the pathological variants $[9,10]$; however, no study has directly compared a group of tau-positive pathologies to a group of TDP-43-positive pathologies to assess for a signature patterns of atrophy by combining all the different pathologies.

The majority of these subjects also had been followed prospectively in the Mayo Clinic Alzheimer's Disease Research Center (ADRC) or Alzheimer's Disease Patient Registry (ADPR). The ADRC began operating as an Alzheimer's Disease Research Program in September 1990 and recruits patients seen in the Department of Neurology, while the ADPR is a population-based study that recruits patients from the Olmsted County region of Minnesota. Both the ADRC and ADPR prospectively follow patients with annual standardized clinical assessments and MRI. The patients that were not recruited into the ADRC or ADPR received similar standardized clinical examinations, MR protocol, and neuropathological examination and were followed prospectively by Behavioral Neurologists in the Department of Neurology. The medical records of all cases were reviewed by a behavioral neurologist (K.A.J.) blinded to pathological diagnosis, for the abstraction of data, including clinical diagnosis at the time of scan, gender, education, age at onset, illness duration, Mini-Mental State Examination (MMSE) [20], and the Clinical Dementia Rating (CDR) scale [21]. A diagnosis of bvFTD, semantic dementia, and progressive non-fluent aphasia was based on consensus criteria [22]. Established were also used to clinically diagnose corticobasal syndrome (CBS) [23], PSP [24], and Alzheimer's disease [25]. Subjects that did not fulfill any of these criteria were classified as 'other'. For patients with more than one MRI scan, the first available in the series was used. We used the first available MRI since the ability to predict pathology would be most useful in clinical practice early in the disease when the patients may still benefit from potential treatments. Furthermore, later on in the disease course all patients are likely to show widespread atrophy and therefore MRI scans at that stage will be less meaningful. All MRI scans were visually assessed (J.L.W.). Scans were rejected for poor quality (such as motion artifact) or the presence of other pathologies (such as stroke, tumor or other structural lesion) that may influence either the structural analysis or clinical presentation.

A group of 35 healthy living controls that had not yet come to postmortem with a volumetric MRI scan were matched by age and gender to the study cohort. All the healthy control subjects were initially recruited into the ADRC or ADPR, and were selected from the ADRC/ADPR database based purely on age and gender. Controls were identified as individuals who (a) were independently functioning community dwellers, (b) did not have active neurologic or psychiatric conditions, (c) had no cognitive complaints, (d) had a normal neurological and neurocognitive examination, and (e) were not taking any psychoactive medications in doses that would affect cognition.

Pathological Assessment and Diagnosis

Neuropathological examinations were performed according to the recommendations of the Consortium to Establish a Registry for Alzheimer's Disease [26]. In all cases, pathological assessment and diagnosis was conducted by one of two expert neuropathologists (D.W.D. or J.E.P.) as previously described [27]. The 
presence of argyrophilic grains [28] and vascular pathology was recorded and Lewy bodies were assessed with $\alpha$-synuclein immunostaining according to established criteria [29]. We also applied NIA-Reagan criteria for the diagnosis of Alzheimer's disease [30]. The criteria used to diagnose each FTLD pathological variant are detailed below.

\section{FTLD-U}

FTLD with ubiquitin-only-immunoreactive changes was diagnosed if there were inclusions that stained positive for TDP-43 and ubiquitin, yet stained negative for tau, neurofilament, and $\alpha$ synuclein, in frontal or temporal cortex, and the hippocampus dentate granular cells without any evidence of motor neuron degeneration as previously described (FTLD-U) [4].

\section{FTLD-MND}

FTLD with motor neuron degeneration was diagnosed if there was evidence of FTLD-U plus lower motor neuron degeneration (loss of anterior horn cells in the spinal cord or hypoglossal motor neurons plus (1) shrunken residual motor neurons, (2) evidence of neuronophagia, (3) Bunina bodies or ubiquitin-immunoreactive intraneuronal inclusions, either skein-like or hyaline-like), corticospinal tract degeneration (myelin and axonal loss and inflammatory cells in the absence of any vascular or other lesions that could account for this finding), or both [31].

Progressive Supranuclear Palsy

Subjects were diagnosed as PSP if there were neuronal loss and gliosis, as well as characteristic tau-positive lesions including tufted astrocytes, coiled bodies and globose neurofibrillary tangles in cardinal nuclei (subthalamic nucleus, thalamic and brainstem nuclei, etc.) that met diagnostic criteria for PSP [32].

\section{Corticobasal Degeneration}

Subjects were given a pathological diagnosis of CBD if there were cortical neuronal loss and gliosis with balloon neurons and tau-positive lesions including astrocytic plaques, corticobasal bodies, and abundant neuropil threads that were located in cardinal regions that met diagnostic criteria for CBD [33].

\section{PiD}

A diagnosis of PiD was made if there were neurofilament-positive balloon neurons and silver and tau-positive rounded Pick bodies in the cerebral cortex, and subcortical gray structures [34].

\section{Sporadic MST}

A diagnosis of sporadic MST was made by the finding of widespread tau-positive globular neuronal and glial inclusions, and absence of mutations in the MAPT gene. Exons 1-5, 7, and 9-13 of the MAPT gene were amplified and directly sequenced. Primers from the intronic sequences surrounding the exons were used so that the entire exon sequence and the splice signals could be analyzed. Standard amplification reactions were done with $50 \mathrm{ng}$ of genomic DNA, and the amplified products were then gel-purified. Asymmetric amplification using the DTCS Quick Start Kit (Beckman Coulter, Fullerton, Calif., USA) was performed. The amplified products were participated and resuspended in sample loading solution and loaded onto a CEQ 200XL DNA Analysis System (Beckman Coulter). The sequences were compared with those of normal controls and with the published MAPT sequence.

FTLD-Tau

A diagnosis of FTLD-tau was made if there was widespread tau deposition in the presence of a mutation in the MAPT gene.

Image Analysis

All MRI studies were performed with a standardized imaging protocol that included a coronal $\mathrm{T}_{1}$-weighted 3-dimensional volumetric spoiled gradient echo (SPGR) sequence with 124 contiguous partitions and 1.6-mm slice thickness $\left(22 \times 16.5 \mathrm{~cm} \mathrm{FOV}, 25^{\circ}\right.$ flip angle). Different scanners were used, but all were GE Signa $1.5 \mathrm{~T}$ with body resonance module gradient sets and transmit-receive single-channel head coils. All scanners undergo a standardized quality control calibration procedure daily, which monitors geometric fidelity over a $200-\mathrm{mm}$ volume along all three cardinal axes, signal-to-noise, and transmit gain, and maintains the scanner within a tight calibration range.

Patterns of cerebral atrophy were assessed using the automated and unbiased technique of voxel-based morphometry (VBM) [35]. An optimized method of VBM was applied using both customized templates and prior probability maps [36], implemented using SPM2 (http://www.fil.ion.ucl.ac.uk/spm). The processing steps were performed as previously described [37]. Briefly, all SPGR images were normalized to a customized template created from all subjects in the study. The spatial normalization was optimized by normalizing the gray matter images to the customized gray matter template. Images were segmented using customized prior probability maps, modulated, and smoothed with an 8- $\mathrm{mm}$ full-width at half-maximum smoothing kernel.

Statistical comparisons were made between the tau-positive group and controls, the TDP-43-positive group and controls, and between the tau-positive and TDP-43-positive groups, correcting for age and gender. A comparison was also performed between tau-positive $(n=15)$ and TDP-43-positive $(n=30)$ groups within only those subjects that had a clinical diagnosis of bvFTD. Age and gender were included in the models as nuisance variables as well as time from onset to scan since this variable was significantly different between the two groups (cf. table 2). Results were assessed after correction for multiple comparisons using the familywise error (FWE) correction ( $\mathrm{p}<0.05)$. We chose the FWE correction for this specific comparison since it is the most stringent correction for multiple comparisons that would rigorously correct for the possibility of false positives, as well as the fact that we had a relatively large number of subjects.

In order to assess how patterns of atrophy relate to disease severity, subjects with bvFTD were also divided into three groups based on their CDR score (CDR 0.5, CDR 1, and CDR 2 or 3 ) and into three groups based on their MMSE score (MMSE 26-30, MMSE 21-25, MMSE 0-20). The MMSE divisions were employed in order to divide the group into equal thirds. Given that no differences were identified between tau-positive and TDP-43-positive cases the analysis investigating disease stage was performed across all subjects with bvFTD, regardless of pathology. Statistical comparisons were performed between each of these groups and controls, including age and gender as nuisance variables. Due to the smaller number of subjects in these analyses a more lenient correction for multiple comparisons was applied using the false discovery rate (FDR) correction at $\mathrm{p}<0.01$. 
Table 1. Subject demographics of all subjects

\begin{tabular}{|c|c|c|c|c|}
\hline & Tau-positive $(\mathrm{n}=37)$ & TDP-43-positive $(\mathrm{n}=44)$ & Controls $(n=35)$ & $\mathrm{p}$ value \\
\hline Male/female & $15 / 22$ & $22 / 22$ & $16 / 19$ & NS \\
\hline Education, years & $12(8-20)$ & $14(8-20)$ & $14(10-20)$ & NS \\
\hline Age at onset, years & $64(42-84)$ & $59(32-83)$ & $\mathrm{NA}$ & $\mathrm{NS}^{1}$ \\
\hline Total illness duration, years & $7(4-15)$ & $7(2-13)$ & NA & $\mathrm{NS}^{1}$ \\
\hline Age at scan, years & $68(48-86)$ & $61(35-84)$ & $64(43-85)$ & NS \\
\hline Onset to scan, years & $3(0-15)$ & $3(0-10)$ & NA & $\mathrm{NS}^{1}$ \\
\hline $\operatorname{MMSE}(/ 30)^{2}$ & $23(10-30)$ & $24(9-29)$ & $30(27-30)$ & $<0.0001$ \\
\hline $\operatorname{CDR}(0-3)^{2}$ & $1(0.5-3)$ & $1(0.5-3)$ & $0(0-0)$ & $<0.0001$ \\
\hline CDR sum of boxes $(/ 18)^{2}$ & $6(0-18)$ & $6(0.5-18)$ & $0(0-0)$ & $<0.0001$ \\
\hline \multicolumn{5}{|l|}{ Clinical diagnoses } \\
\hline bvFTD & $41 \%$ & $68 \%$ & NA & \\
\hline $\mathrm{SD}$ & $0 \%$ & $16 \%$ & NA & \\
\hline PNFA & $16 \%$ & $4.5 \%$ & NA & \\
\hline CBS & $30 \%$ & $4.5 \%$ & NA & \\
\hline $\mathrm{AD}$ & $5 \%$ & $7 \%$ & NA & \\
\hline Other & $8 \%$ & $0 \%$ & NA & \\
\hline \multicolumn{5}{|l|}{ Secondary pathologies } \\
\hline NIA-Reagan criteria for $\mathrm{AD}$ & $0 \%$ & $0 \%$ & NA & \\
\hline Lewy bodies & $3 \%$ & $0 \%$ & NA & \\
\hline Argyrophilic grains & $26 \%$ & $14 \%$ & NA & \\
\hline Cerebrovascular pathology & $10 \%$ & $11 \%$ & NA & \\
\hline
\end{tabular}

Data is shown in median (range). $\mathrm{AD}=$ Alzheimer's disease; bvFTD = behavioral variant frontotemporal dementia; $\mathrm{CBS}=$ corticobasal syndrome; CDR = Clinical Dementia Rating Scale; MMSE = Mini-Mental State Examination; NA = not applicable; NIA-Reagan = National Institute of Aging and Reagan Institute; NS = not significant; PNFA = progressive non-fluent aphasia; $\mathrm{SD}=$ semantic dementia. p value shows the result from Kruskal-Wallis tests across all three groups.

${ }^{1}$ Kruskal-Wallis test performed across only tau-positive and TDP-43-positive groups. ${ }^{2}$ MMSE was available in 23 tau-positive, 25 TDP-43-positive and 35 controls; CDR in 29 tau-positive, 30 TDP-43-positive and 35 controls.

Table 2. Subject demographics of tau-positive and TDP-43-positive subjects with a clinical diagnosis of bvFTD

\begin{tabular}{lccl}
\hline & $\begin{array}{l}\text { Tau- } \\
\text { positive } \\
(\mathrm{n}=15)\end{array}$ & $\begin{array}{l}\text { TDP-43- } \\
\text { positive } \\
(\mathrm{n}=30)\end{array}$ & $\begin{array}{l}\mathrm{p} \\
\text { value }\end{array}$ \\
\hline Male/female & $8 / 7$ & $15 / 15$ & $\mathrm{NS}$ \\
Education, years & $15(9-20)$ & $14(8-20)$ & $\mathrm{NS}$ \\
Age at onset, years & $57(42-76)$ & $57(32-83)$ & $\mathrm{NS}$ \\
Total illness duration, years & $7(4-15)$ & $6(2-13)$ & 0.05 \\
Age at scan, years & $63(48-79)$ & $58(34-84)$ & NS \\
Onset to scan, years & $5(1-15)$ & $3(1-8)$ & 0.03 \\
MMSE $(/ 30)^{1}$ & $21(10-28)$ & $25(11-29)$ & NS \\
CDR $(0-3)^{1}$ & $1(0.5-3)$ & $1(0.5-3)$ & NS \\
CDR sum of boxes $(/ 18)^{1}$ & $6(2-18)$ & $6(2-18)$ & NS \\
\hline
\end{tabular}

Data is shown in median (range). CDR = Clinical Dementia Rating Scale; MMSE = Mini-Mental State Examination; NS = not significant. p value shows the result from Mann-Whitney $U$ tests across tau-positive and TDP-43-positive groups.

${ }^{1}$ MMSE was available in 6 tau-positive and 18 TDP-43-positive; CDR in 12 tau-positive and 19 TDP-43-positive.

\section{Statistics}

Statistical analyses were performed utilizing the JMP computer software (JMP Software, Version 6.0.0; SAS Institute, Inc., Cary, N.C., USA) with statistical significance set at $\mathrm{p}<0.05$. $\chi^{2}$ analysis was used for group comparisons of nominal data, while Kruskal-Wallis test and Mann-Whitney $U$ analysis were used for continuous data.

\section{Results}

\section{Subject Demographics}

Subject demographics and clinical diagnoses are shown in table 1 . There were no differences between the tau-positive group, TDP-43-positive group, and controls in age at scan, education or gender ratio. There were significant differences across the three groups in the cognitive/functional test scores, although these test scores did not differ between disease groups. The tau-positive and TDP-43-positive group also did not differ in age at onset, total illness duration, and time from onset to scan. The 
Table 3. Subject demographics of all subjects with a diagnosis of bvFTD split by CDR and MMSE

\begin{tabular}{|c|c|c|c|c|c|c|c|c|}
\hline & \multicolumn{4}{|l|}{ CDR } & \multicolumn{4}{|l|}{ MMSE } \\
\hline & $0.5(\mathrm{n}=7)$ & $1(\mathrm{n}=15)$ & $2-3(n=9)$ & $\mathrm{p}$ value & $26-30(n=8)$ & $21-25(n=8)$ & $0-20(\mathrm{n}=8)$ & $\mathrm{p}$ value \\
\hline Male/female & $3 / 4$ & $7 / 8$ & $4 / 5$ & NS & $4 / 4$ & $4 / 4$ & $1 / 7$ & NS \\
\hline Education, years & $18(14-20)$ & $12(8-20)$ & $16(12-18)$ & NS & $17(12-20)$ & $14(8-20)$ & $13(9-16)$ & NS \\
\hline Age at onset, years & $65(52-83)$ & $58(40-77)$ & $50(44-69)$ & NS & $59(45-65)$ & $66(43-71)$ & $50(42-83)$ & NS \\
\hline Total illness duration, years & $5(4-10)$ & $7(2-13)$ & $10(2-15)$ & NS & $7(3-13)$ & $8(6-13)$ & $7(2-14)$ & NS \\
\hline Age at scan, years & $69(55-84)$ & $64(41-79)$ & $55(52-75)$ & NS & $61(50-68)$ & $70(49-79)$ & $54(50-84)$ & NS \\
\hline Onset to scan, years & $2(1-7)$ & $4(1-6)$ & $4(1-15)$ & NS & $3(1-6)$ & $3(2-6)$ & $4(1-8)$ & NS \\
\hline $\operatorname{MMSE}(/ 30)$ & $29(21-35)$ & $24(11-27)$ & $19(11-26)$ & NS & $28(26-29)$ & $24(21-25)$ & $15(10-20)$ & $<0.0001$ \\
\hline $\operatorname{CDR}(0-3)$ & $28(15-29)$ & $1(1-1)$ & $2(2-3)$ & $<0.0001$ & $0.5(0.5-2)$ & $1(0.5-2)$ & $2(0.5-3)$ & NS \\
\hline CDR sum of boxes $(/ 18)$ & $0.5(0.5-0.5)$ & $6(4-8)$ & $13(9-18)$ & $<0.0001$ & $5(2-9)$ & $7(5-9)$ & $9(6-18)$ & 0.01 \\
\hline \multicolumn{9}{|l|}{ Pathological diagnoses } \\
\hline Tau-positive & $57 \%$ & $60 \%$ & $56 \%$ & & $12 \%$ & $25 \%$ & $38 \%$ & \\
\hline TDP-43 positive & $43 \%$ & $40 \%$ & $44 \%$ & & $86 \%$ & $75 \%$ & $62 \%$ & \\
\hline
\end{tabular}

Data is shown in median (range). CDR = Clinical Dementia Rating Scale; MMSE = Mini-Mental State Examination; NS = not significant. $p$ value shows the result from Mann-Whitney $U$ tests across the three CDR groups and across the three MMSE groups.

majority of the TDP-43-positive subjects had a clinical diagnosis of bvFTD, whereas the most common diagnoses in the tau-positive groups were bvFTD and CBS. Secondary pathologies were minimal in this cohort. When only subjects with a clinical diagnosis of bvFTD were assessed (table 2), the only difference between tau-positive and TDP-43-positive groups was in the time from disease onset to scan and total illness duration. The bvFTD taupositive group consisted of 6 subjects with FTLD-tau, 4 with PiD, 2 with CBD, 2 with PSP, and 1 with MST. The bvFTD TDP-43-positive group consisted of 20 subjects with FTLD-U and 10 subjects with FTLD-MND.

Table 3 shows the demographics of the bvFTD subjects when divided by disease severity, either using the CDR or the MMSE. The three groups defined by CDR, and the three groups defined by MMSE, were similar in demographics. The proportion of subjects with tau-positive disease remained constant across the different disease severity groups.

\section{Tau-Positive versus TDP-43-Positive}

The tau-positive and TDP-43-positive groups both showed a widespread pattern of predominantly frontotemporal gray matter loss compared to controls. Gray matter loss was identified in the medial and lateral frontal lobe, orbitofrontal cortex, insula, medial temporal lobe, posterior lateral temporal lobe, parietal lobe, thala- mus and brainstem in the TDP-43-positive group (fig. 1). Gray matter loss was observed in the same regions in the tau-positive group, although was slightly less severe in the temporal lobes and loss was also observed in the putamen bilaterally (fig. 1). A direct comparison between the TDP-43-positive and tau-positive groups failed to find any regions that were involved to a greater degree in the tau-positive group even when the data was uncorrected for multiple comparisons. The TDP-43-positive group had a few scattered regions of greater loss in the temporal lobes compared to the tau-positive group (uncorrected, $\mathrm{p}<0.001$ ), although these regions did not survive a correction for multiple comparisons using the FWE correction $(\mathrm{p}<0.05)$, or the more lenient FDR correction $(\mathrm{p}<0.01)$.

When only subjects with a clinical diagnosis of bvFTD were analyzed, once again a pattern of frontotemporal gray matter loss was observed in both TDP-43-positive and tau-positive groups compared to controls (fig. 2). Striatal gray matter loss was observed in the tau-positive group in the comparison to controls but not in the TDP43-positive group compared to controls. However, the tau-positive group had a significantly longer time from onset to scan than the TDP-43-positive group. Therefore, when we performed a direct comparison between tau and TDP-43-positive groups, we corrected for time from onset to scan. On direct comparison, the tau-positive group 
Fig. 1. Patterns of gray matter loss identified in tau-positive and TDP-43-positive pathology groups compared to age- and gender-matched controls. Results are shown corrected for multiple comparisons using the FWE correction $(\mathrm{p}<0.05)$ on a $3 \mathrm{D}$ surface render as well as representative coronal slices through the customized template.
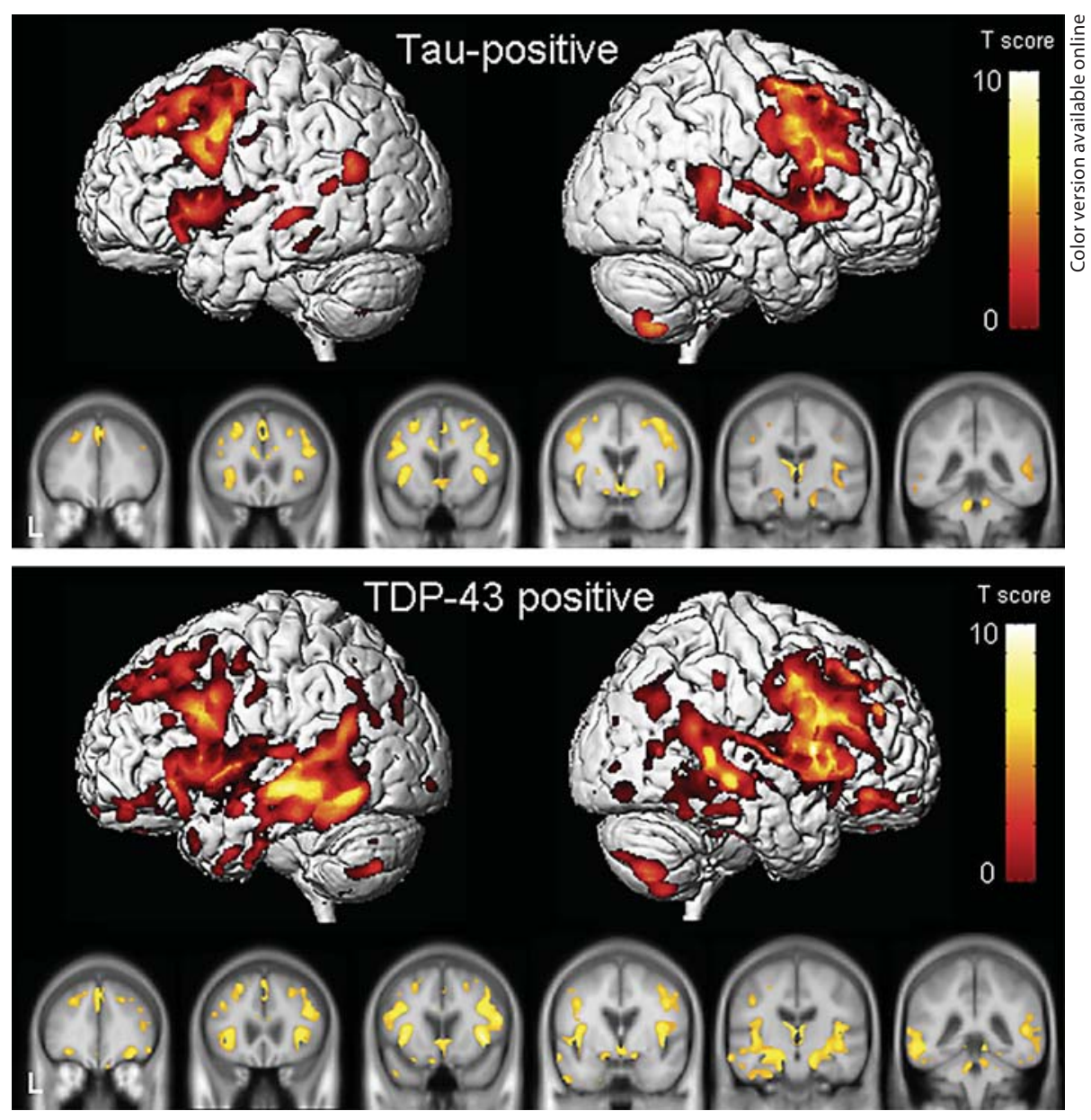

did not have significantly more striatal atrophy than the TDP-43 group. In fact, no differences were observed between the tau-positive and TDP-43-positive group on direct comparison (uncorrected, $\mathrm{p}<0.001$ ).

\section{Disease Severity}

Patients with bvFTD who had a CDR score of 0.5 showed gray matter loss predominantly in the medial, orbital and dorsolateral aspects of the frontal lobes, as well as the anterior insular, anterior cingulate gyrus, and anterior hippocampus compared to controls (fig. 3). More severe involvement of these regions was identified at CDR 1 with additional widespread involvement of the temporal lobes as well as the posterior cingulate gyrus and parietal lobe (fig. 3). Once again, a more severe pattern of loss was observed in patients who had a CDR of 2 or 3 with more severe involvement of all structures and additional bilateral involvement of the striatum (fig. 3). Almost identical patterns of loss were observed in the dif- ferent MMSE groups (fig. 4), with involvement of the frontal lobes and hippocampi at MMSE 26-30, additional involvement of the temporal and parietal lobes at MMSE 21-25 and then involvement of the striatum at MMSE 0-20.

\section{Discussion}

This is the largest study to have assessed patterns of atrophy in autopsy-confirmed FTLD. While there seemed to be some small differences across tau-positive and TDP43-positive groups, such as greater temporal lobe involvement in TDP-43-positive disease, there appeared to be no signature patterns of atrophy of either tau or TDP-43 on direct comparison. This finding persisted even when the potential confounder of clinical phenotype was removed and the patterns of atrophy were assessed only in subjects with a clinical diagnosis of bvFTD. 
Fig. 2. Patterns of gray matter loss identified in the tau-positive and TDP-43-positive pathology subjects with a clinical diagnosis of bvFTD compared to age- and gender-matched controls. Results are shown corrected for multiple comparisons using the FWE correction $(\mathrm{p}<0.05)$ on a $3 \mathrm{D}$ surface render as well as representative coronal slices through the customized template.
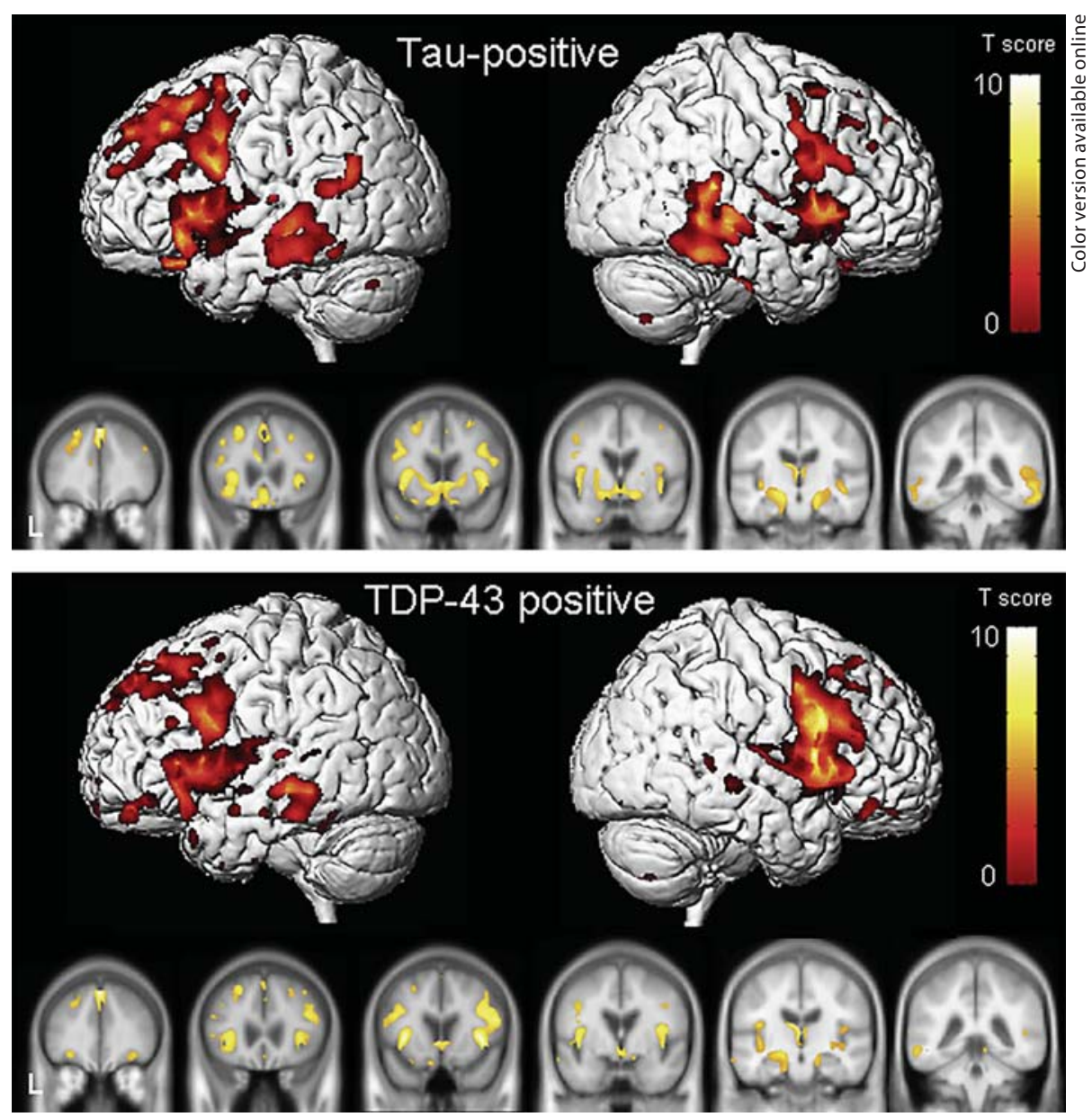

There are a couple of explanations for these findings. Firstly, it is possible that the syndrome of bvFTD is a very homogeneous entity in which the underlying anatomical involvement, independent of pathological substrate, is accounting for the syndrome. Secondly, the variability in patterns of atrophy that we have demonstrated in each specific tau-positive pathology (i.e. CBD, PSP, FTLD-tau and PiD) $[9,11,38]$ and each specific TDP-43-positive pathology (FTLD-U and FTLD-MND) [10] (table 4) may have resulted in an overall absence of any meaningful signature for tau or TDP-43. We have demonstrated for example that patients who have bvFTD and FTLD-U have a different pattern of atrophy from patients who have bvFTD and FTLD-MND [10]. In order for a signature pattern of atrophy to exist, this signature would have to be present across most, if not all, of the different pathological subtypes associated with the specific protein. Importantly, although a signature pattern of atrophy does not appear to exist for tau or TDP-43, the distinct patterns of atrophy of the specific pathological subtypes that we have previously demonstrated $[9-11,38]$ can still allow the prediction, indirectly, of the presence of tau and TDP-43. For example, 2 patients may present with different patterns of atrophy: one with a frontoparietal pattern distinctive of CBD (table 4) and the other with superior cerebellar peduncle atrophy distinctive of PSP (table 4). These are two completely distinct patterns of atrophy demonstrating that tau does not have one signature pattern of atrophy, yet both patterns are indicative of underlying tau pathology.

The results from a couple of small studies have implied that there may be differences between tau-positive and tau-negative FTLD, although none have looked directly at TDP-43-positive FTLD, but only at FTLD-U. These results conflict with our original publication where no differences between tau-positive and tau-negative FTLD were identified [39]. One of these small studies found a greater degree of striatal atrophy in tau-positive subjects 


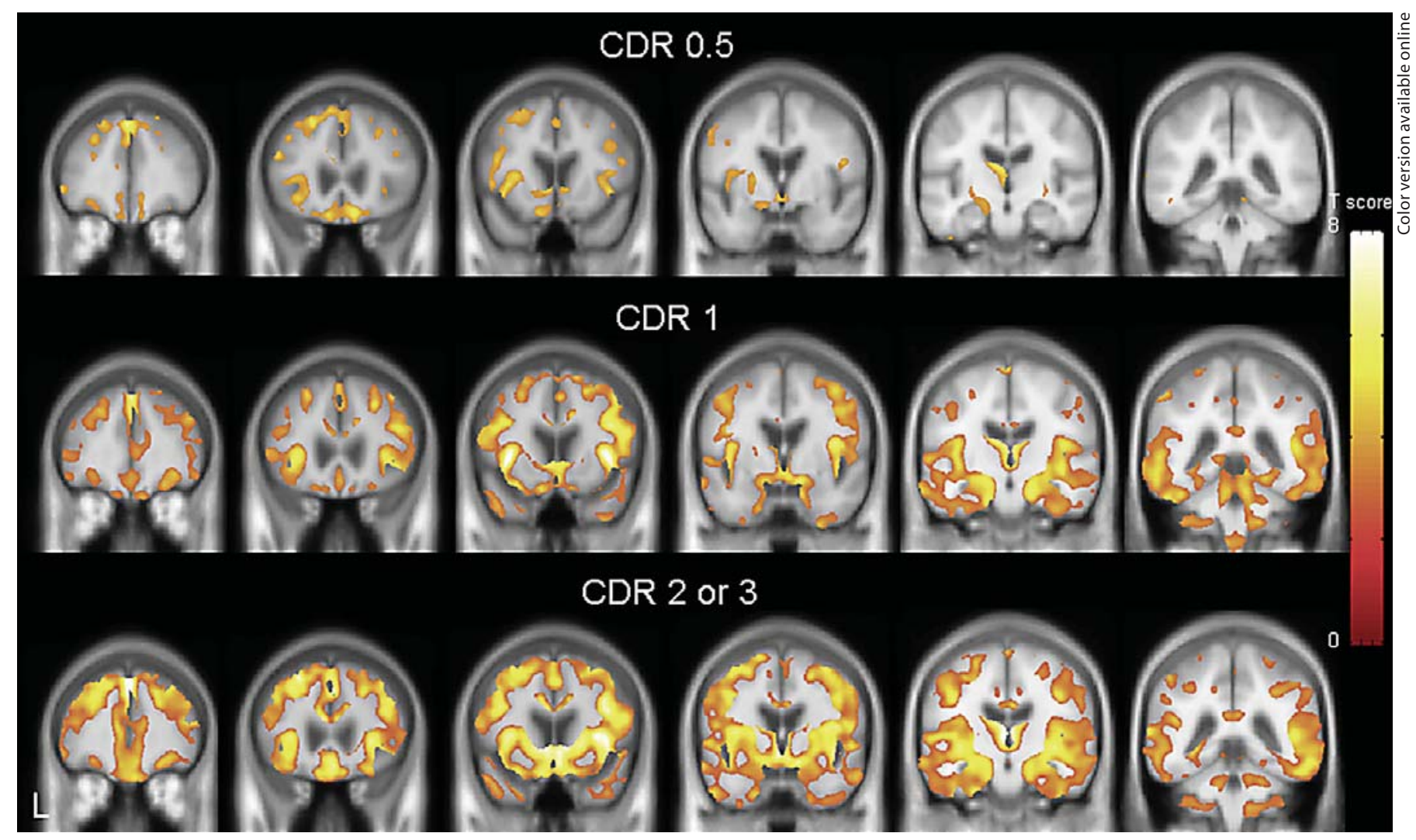

Fig. 3. Patterns of gray matter loss in subjects with bvFTD grouped according to CDR score. Results are shown corrected for multiple comparisons using the FDR correction $(\mathrm{p}<0.01)$ on representative coronal slices through the customized template.

compared with tau-negative subjects [40]. There was a suggestion that striatal gray matter loss was more severe in subjects with bvFTD and tau-positive pathology compared to TDP-43-positive pathology in our study; however, after adjusting for time from onset to scan there were no differences between the tau-positive and TDP43-positive groups on direct comparison. Interestingly, our analyses performed across disease severities showed that striatal atrophy occurs almost exclusively in subjects with an advanced disease severity (CDR of $2 / 3$ or MMSE 0-20). Similarly, the performance on the MMSE was worse in the tau-positive group in the earlier study that identified more striatal atrophy in tau-positive cases [40] suggesting that the finding of striatal differences could have been confounded by differences in disease severity. Parietal atrophy has also been suggested to be associated with tau pathology [41]. This finding most likely reflects the presence of one specific tau pathology, i.e. CBD pathology, which has been shown to be associated with frontoparietal atrophy [9]. Hence, parietal lobe atrophy can indirectly predict tau but is not a signature of all tau cases.

The analysis by cognitive/functional score showed that the severity and topographic distribution of gray matter loss in bvFTD increased with increasing disease severity, as measured by the CDR or MMSE score. The results from the grouping by CDR and MMSE were very similar. The subjects with very mild disease showed gray matter loss in the frontal lobes, involving dorsolateral, medial and orbital regions, the anterior insula, and the hippocampus. The anterior cingulate was also observed in subjects with mild CDR scores of 0.5 . One could infer from these results that these are the earliest regions to become involved in bvFTD. The frontal lobes, insula and anterior cingulate have all been implicated in the regulation of behavior and personality [42-46]; features which occur early in subjects with bvFTD [22, 47, 48]. The finding of hippocampal loss in mild subjects is somewhat unexpected, although the 


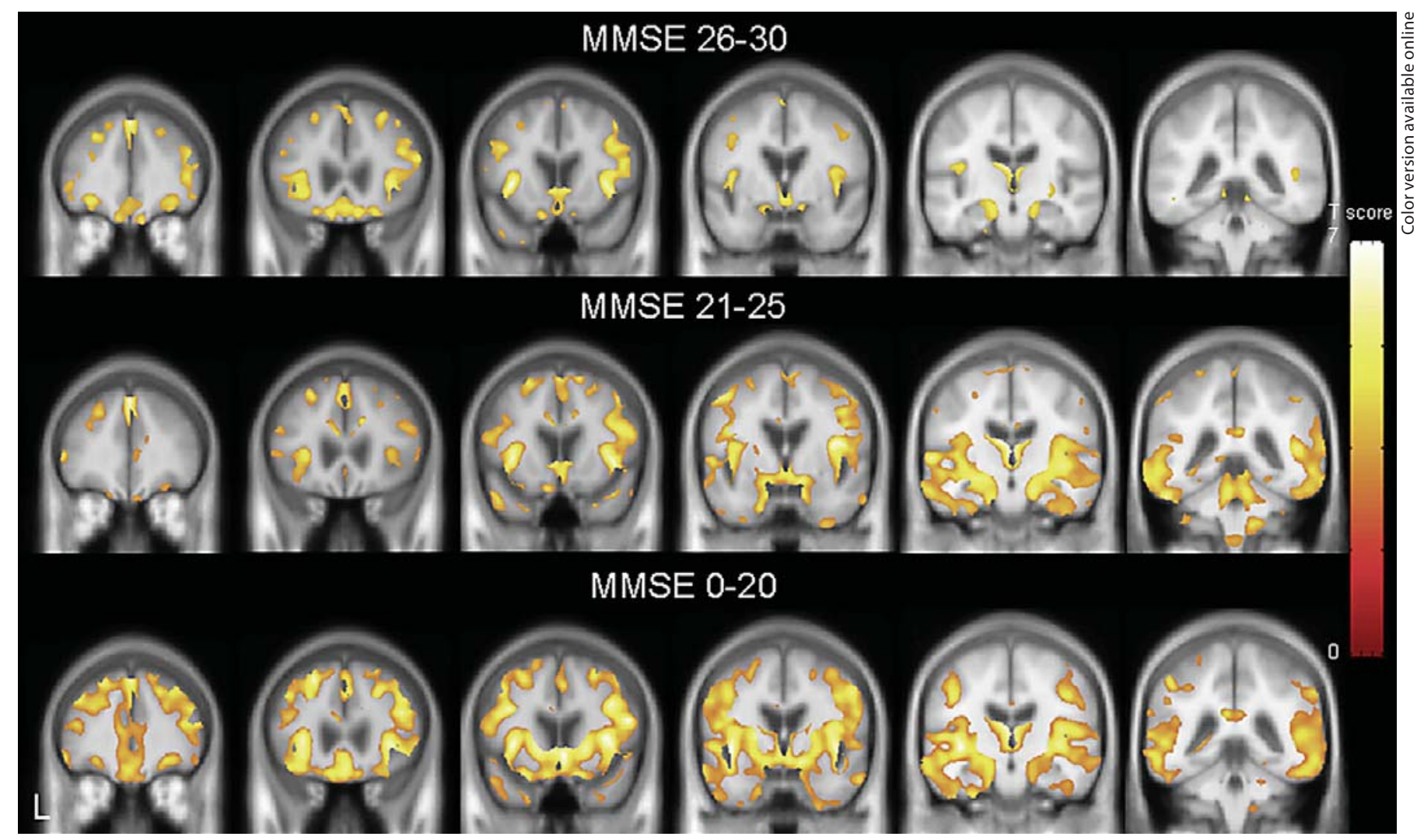

Fig. 4. Patterns of gray matter loss in subjects with bvFTD grouped according to MMSE score. Results are shown corrected for multiple comparisons using the FDR correction $(\mathrm{p}<0.01)$ on representative coronal slices through the customized template.

Table 4. Distinct patterns of atrophy associated with each tau- and TDP-43-positive pathological subtype as previously published

\begin{tabular}{llc}
\hline Group & Predominant regions of gray matter loss & Ref. \\
\hline $\begin{array}{l}\text { Tau-positive } \\
\text { PiD }\end{array}$ & Anterior frontal lobes & 11 \\
FTLD-tau & Anteromedial temporal lobes & 11,38 \\
CBD & Frontoparietal cortex and rostral basal ganglia & 9 \\
PSP & Brainstem and superior premotor cortex & 9 \\
TDP-43-positive & & 10,11 \\
FTLD-U & Anteromedial and posterior temporal lobes & 10 \\
FTLD-MND & Mid to posterior frontal lobes & \\
\hline
\end{tabular}

PiD = Pick's disease; FTLD-tau = FTLD with mutations in microtubule-associated protein tau; $C B D=$ corticobasal degeneration; PSP = progressive supranuclear palsy; FTLD-U = FTLD with ubiquitin-positive immunoreactive inclusions; FTLD-MND = FTLD with ubiquitin-immunoreactive inclusions with motor neuron degeneration. 
hippocampus has been shown to be atrophic in subjects with clinically defined FTD [49-51] and pathologically confirmed bvFTD subjects [52]. As the disease severity increased, we observed increasing loss in these regions, as well as much more severe and widespread involvement of the temporal and parietal lobe, posterior cingulate and brainstem. Interestingly, severe involvement of the striatum, particularly the putamen, was only observed in subjects that had a severe disease severity with CDR scores of 2 or 3 or MMSE scores of $0-20$.

One previous imaging study has staged subjects with bvFTD by CDR score only, not MMSE, and also did not have pathological confirmation [53]. Similarly, that study demonstrated involvement of the frontal lobe, insula and hippocampus in subjects with mild CDR, and showed progression into the parietal lobes and striatum as the CDR score increased [53]. In contrast to our results, they did not find widespread involvement of the temporal lobes even at a CDR score of 2 or 3 . As a result, our results appear to conform more closely with the proposed pathological staging scheme for FTD, in which early loss of the orbital and medial frontal lobes and hippocampus is followed by more widespread temporal lobe involvement, including the anterior temporal pole and inferior temporal gyri [54]. Furthermore, the pathological staging scheme also demonstrates that severe striatal damage is a feature of more advanced disease [54].

It is important, however, to recognize the fact that the patterns of atrophy that we observed as disease severity increases are likely to be highly dependent on the cognitive/functional tests that one chooses to analyze. The MMSE and CDR are the most widely recognized cognitive/functional tests of disease severity, yet both were developed for Alzheimer's disease and therefore neither is a particularly good measure of disease severity or progression in bvFTD which is dominated by behavioral and personality changes. Both tests are also particularly affected by problems with language and executive function, which can be affected in bvFTD. Therefore, if a test that assessed another cognitive domain was selected to measure disease severity, these patients may perform differently and may end up being categorized differently. It is also important to remember that this is a group analysis, and therefore, while we can make inferences concerning the patterns of progression in bvFTD, we cannot tell whether all subjects follow the same pattern of progression. Future studies will need to examine the patterns of atrophy in individual subjects in order to assess variability in patterns of progression.

We have demonstrated that neither tau nor TDP-43 have a distinct pattern of atrophy, most likely reflecting the fact that the tau and TDP-43 groups consisted of taupositive and TDP-43-positive subgroups, each having their own distinct pattern of atrophy. Therefore, predicting tau or TDP-43 pathology will depend on predicting the individual pathological subtypes which in turn will allow the prediction of tau and TDP-43.

\section{Acknowledgements}

This study was supported by the NIH Roadmap Multidisciplinary Clinical Research Career Development Award Grant (K12/NICHD)-HD49078, by grants P50 AG16574, U01 AG06786 and R01 AG11378 from the National Institute on Aging, Bethesda Md., and the generous support of the Robert H. and Clarice Smith and Abigail Van Buren Alzheimer's Disease Research Program of the Mayo Foundation, USA, the Alexander Family Alzheimer's Disease Research Professorship of the Mayo Foundation, and the NIH Construction Grant (NIH C06 RR018898).
References

MRI in Autopsy-Confirmed FTLD
1 Arai T, Hasegawa M, Akiyama H, Ikeda K, Nonaka T, Mori H, Mann D, Tsuchiya K, Yoshida M, Hashizume Y, Oda T: TDP-43 is a component of ubiquitin-positive tau-negative inclusions in frontotemporal lobar degeneration and amyotrophic lateral sclerosis. Biochem Biophys Res Commun 2006; 351:602-611.

2 Neumann M, Sampathu DM, Kwong LK, Truax AC, Micsenyi MC, Chou TT, Bruce J, Schuck T, Grossman M, Clark CM, McCluskey LF, Miller BL, Masliah E, Mackenzie IR, Feldman H, Feiden W, Kretzschmar HA, Trojanowski JQ, Lee VM: Ubiquitinated TDP-43 in frontotemporal lobar degeneration and amyotrophic lateral sclerosis. Science 2006;314:130-133.
3 Josephs KA: Frontotemporal dementia and related disorders: deciphering the enigma. Ann Neurol 2008;64:4-14.

-4 Josephs KA, Holton JL, Rossor MN, Godbolt AK, Ozawa T, Strand K, Khan N, Al-Sarraj S, Revesz T: Frontotemporal lobar degeneration and ubiquitin immunohistochemistry. Neuropathol Appl Neurobiol 2004;30:369373.

5 Forman MS, Farmer J, Johnson JK, Clark CM, Arnold SE, Coslett HB, Chatterjee A, Hurtig HI, Karlawish JH, Rosen HJ, Van Deerlin V, Lee VM, Miller BL, Trojanowski JQ, Grossman M: Frontotemporal dementia: clinicopathological correlations. Ann Neurol 2006;59:952-962. 
-6 Hodges JR, Davies RR, Xuereb JH, Casey B, Broe M, Bak TH, Kril JJ, Halliday GM: Clinicopathological correlates in frontotemporal dementia. Ann Neurol 2004;56:399-406.

$\checkmark 7$ Josephs KA, Petersen RC, Knopman DS, Boeve BF, Whitwell JL, Duffy JR, Parisi JE, Dickson DW: Clinicopathologic analysis of frontotemporal and corticobasal degenerations and PSP. Neurology 2006;66:41-48.

$\checkmark 8$ Kertesz A, McMonagle P, Blair M, Davidson W, Munoz DG: The evolution and pathology of frontotemporal dementia. Brain 2005; 128 : 1996-2005

-9 Josephs KA, Whitwell JL, Dickson DW, Boeve BF, Knopman DS, Petersen RC, Parisi JE, Jack CR Jr: Voxel-based morphometry in autopsy proven PSP and CBD. Neurobiol Aging 2008;29:280-289.

10 Whitwell JL, Jack CR Jr, Senjem ML, Josephs KA: Patterns of atrophy in pathologically confirmed FTLD with and without motor neuron degeneration. Neurology 2006;66: 102-104.

-11 Whitwell JL, Josephs KA, Rossor MN, Stevens JM, Revesz T, Holton JL, Al-Sarraj S, Godbolt AK, Fox NC, Warren JD: Magnetic resonance imaging signatures of tissue pathology in frontotemporal dementia. Arch Neurol 2005;62:1402-1408.

-12 Johnson JK, Diehl J, Mendez MF, Neuhaus J, Shapira JS, Forman M, Chute DJ, Roberson ED, Pace-Savitsky C, Neumann M, Chow TW, Rosen HJ, Forstl H, Kurz A, Miller BL: Frontotemporal lobar degeneration: demographic characteristics of 353 patients. Arch Neurol 2005;62:925-930.

-13 Busatto GF, Garrido GE, Almeida OP, Castro CC, Camargo $\mathrm{CH}$, Cid CG, Buchpiguel CA, Furuie S, Bottino CM: A voxel-based morphometry study of temporal lobe gray matter reductions in Alzheimer's disease. Neurobiol Aging 2003;24:221-231.

-14 Ferrarini L, Palm WM, Olofsen H, van der Landen R, Jan Blauw G, Westendorp RG, Bollen EL, Middelkoop HA, Reiber JH, van Buchem MA, Admiraal-Behloul F: MMSE scores correlate with local ventricular enlargement in the spectrum from cognitively normal to Alzheimer disease. Neuroimage 2008;39:1832-1838.

-15 Fox NC, Scahill RI, Crum WR, Rossor MN: Correlation between rates of brain atrophy and cognitive decline in ad. Neurology 1999; 52:1687-1689.

16 Frisoni GB, Testa C, Zorzan A, Sabattoli F, Beltramello A, Soininen H, Laakso MP: Detection of gray matter loss in mild Alzheimer's disease with voxel-based morphometry. J Neurol Neurosurg Psychiatry 2002;73: 657-664.

- 17 Jack CR Jr, Petersen RC, Xu YC, Waring SC, O’Brien PC, Tangalos EG, Smith GE, Ivnik RJ, Kokmen E: Medial temporal atrophy on MRI in normal aging and very mild Alzheimer's disease. Neurology 1997;49:786794.
Stout JC, Jernigan TL, Archibald SL, Salmon DP: Association of dementia severity with cortical gray matter and abnormal white matter volumes in dementia of the Alzheimer type. Arch Neurol 1996;53:742-749.

19 Yamaguchi S, Meguro K, Shimada M, Ishizaki J, Yamadori A, Sekita Y: Five-year retrospective changes in hippocampal atrophy and cognitive screening test performances in very mild Alzheimer's disease: the Tajiri project. Neuroradiology 2002;44:43-48.

20 Folstein MF, Folstein SE, McHugh PR: 'MiniMental State'. A practical method for grading the cognitive state of patients for the clinician. J Psychiatr Res 1975;12:189-198.

21 Hughes CP, Berg L, Danziger WL, Coben LA, Martin RL: A new clinical scale for the staging of dementia. Br J Psychiatry 1982; 140:566-572.

22 Neary D, Snowden JS, Gustafson L, Passant U, Stuss D, Black S, Freedman M, Kertesz A Robert PH, Albert M, Boone K, Miller BL, Cummings J, Benson DF: Frontotemporal lobar degeneration: a consensus on clinical diagnostic criteria. Neurology 1998;51: 1546-1554.

23 Boeve BF, Lang AE, Litvan I: Corticobasal degeneration and its relationship to progressive supranuclear palsy and frontotemporal dementia. Ann Neurol 2003;54(suppl 5): S15-S19.

24 Litvan I, Agid Y, Calne D, Campbell G, Dubois B, Duvoisin RC, Goetz CG, Golbe LI, Grafman J, Growdon JH, Hallett M, Jankovic J, Quinn NP, Tolosa E, Zee DS: Clinical research criteria for the diagnosis of progressive supranuclear palsy (Steele-RichardsonOlszewski syndrome): report of the NINDSSPSP International Workshop. Neurology 1996;47:1-9.

25 McKhann G, Drachman D, Folstein M, Katzman R, Price D, Stadlan EM: Clinical diagnosis of Alzheimer's disease: report of the NINCDS-ADRDA Work Group under the auspices of Department of Health and Human Services Task Force on Alzheimer's Disease. Neurology 1984;34:939-944.

-26 Mirra SS, Heyman A, McKeel D, Sumi SM, Crain BJ, Brownlee LM, Vogel FS, Hughes JP, van Belle $G$, Berg L: The consortium to establish a registry for Alzheimer's disease (CERAD). II. Standardization of the neuropathologic assessment of Alzheimer's disease. Neurology 1991;41:479-486.

27 Knopman DS, Parisi JE, Salviati A, FloriachRobert M, Boeve BF, Ivnik RJ, Smith GE, Dickson DW, Johnson KA, Petersen LE, McDonald WC, Braak H, Petersen RC: Neuropathology of cognitively normal elderly. J Neuropathol Exp Neurol 2003;62:10871095.

28 Braak H, Braak E: Cortical and subcortical argyrophilic grains characterize a disease associated with adult onset dementia. Neuropathol Appl Neurobiol 1989;15:13-26.
29 McKeith IG, Dickson DW, Lowe J, Emre M, O'Brien JT, Feldman H, Cummings J, Duda JE, Lippa C, Perry EK, Aarsland D, Arai H, Ballard CG, Boeve B, Burn DJ, Costa D, Del Ser T, Dubois B, Galasko D, Gauthier S, Goetz CG, Gomez-Tortosa E, Halliday G, Hansen LA, Hardy J, Iwatsubo T, Kalaria RN, Kaufer D, Kenny RA, Korczyn A, Kosaka K, Lee VM, Lees A, Litvan I, Londos E, Lopez OL, Minoshima S, Mizuno Y, Molina JA, Mukaetova-Ladinska EB, Pasquier F, Perry RH, Schulz JB, Trojanowski JQ, Yamada M: Diagnosis and management of dementia with Lewy bodies: Third Report of the DLB Consortium. Neurology 2005;65:18631872 .

30 Hyman BT, Trojanowski JQ: Consensus recommendations for the postmortem diagnosis of Alzheimer disease from the National Institute on Aging and the Reagan Institute Working Group on diagnostic criteria for the neuropathological assessment of Alzheimer disease. J Neuropathol Exp Neurol 1997;56: 1095-1097.

>31 Josephs KA, Parisi JE, Knopman DS, Boeve BF, Petersen RC, Dickson DW: Clinically undetected motor neuron disease in pathologically proven frontotemporal lobar degeneration with motor neuron disease. Arch Neurol 2006;63:506-512.

>32 Hauw JJ, Daniel SE, Dickson D, Horoupian DS, Jellinger K, Lantos PL, McKee A, Tabaton M, Litvan I: Preliminary NINDS neuropathologic criteria for Steele-RichardsonOlszewski syndrome (progressive supranuclear palsy). Neurology 1994;44:2015-2019.

-33 Dickson DW, Bergeron C, Chin SS, Duyckaerts C, Horoupian D, Ikeda K, Jellinger K, Lantos PL, Lippa CF, Mirra SS, Tabaton M, Vonsattel JP, Wakabayashi K, Litvan I: Office of rare diseases neuropathologic criteria for corticobasal degeneration. J Neuropathol Exp Neurol 2002;61:935-946.

34 Dickson DW: Neuropathology of Pick's disease. Neurology 2001;56:S16-S20.

35 Ashburner J, Friston KJ: Voxel-based morphometry - the methods. Neuroimage 2000; 11:805-821

36 Senjem ML, Gunter JL, Shiung MM, Petersen RC, Jack CR Jr: Comparison of different methodological implementations of voxelbased morphometry in neurodegenerative disease. Neuroimage 2005;26:600-608.

$\checkmark 37$ Whitwell JL, Weigand SD, Shiung MM, Boeve BF, Ferman TJ, Smith GE, Knopman DS, Petersen RC, Benarroch EE, Josephs KA, Jack CR Jr: Focal atrophy in dementia with Lewy bodies on MRI: a distinct pattern from Alzheimer's disease. Brain 2007;130:708719.

>38 Whitwell JL, Jack CR, Boeve BF, Senjem ML, Baker M, Rademakers R, Ivnik RJ, Knopman DS, Wszolek ZK, Petersen RC, Josephs KA: Voxel-based morphometry patterns of atrophy in FTLD with mutations in MAPT or PGRN. Neurology 2009;72:813-820. 
-39 Whitwell JL, Warren JD, Josephs KA, Godbolt AK, Revesz T, Fox NC, Rossor MN: Voxel-based morphometry in tau-positive and tau-negative frontotemporal lobar degenerations. Neurodegener Dis 2004;1:225-230.

40 Kim EJ, Rabinovici GD, Seeley WW, Halabi C, Shu H, Weiner MW, DeArmond SJ, Trojanowski JQ, Gorno-Tempini ML, Miller BL, Rosen HJ: Patterns of MRI atrophy in taupositive and ubiquitin-positive frontotemporal lobar degeneration. J Neurol Neurosurg Psychiatry 2007;78:1375-1378.

-41 Grossman M, Libon DJ, Forman MS, Massimo L, Wood E, Moore P, Anderson C, Farmer J, Chatterjee A, Clark CM, Coslett HB, Hurtig HI, Lee VM, Trojanowski JQ: Distinct antemortem profiles in patients with pathologically defined frontotemporal dementia. Arch Neurol 2007;64:1601-1609.

-42 Hoefer M, Allison SC, Schauer GF, Neuhaus JM, Hall J, Dang JN, Weiner MW, Miller BL, Rosen HJ: Fear conditioning in frontotemporal lobar degeneration and Alzheimer's disease. Brain 2008;131:1646-1657.

$\checkmark 43$ Rosen HJ, Allison SC, Schauer GF, GornoTempini ML, Weiner MW, Miller BL: Neuroanatomical correlates of behavioural disorders in dementia. Brain 2005;128:26122625.
44 Small DM, Zatorre RJ, Dagher A, Evans AC, Jones-Gotman M: Changes in brain activity related to eating chocolate: from pleasure to aversion. Brain 2001;124:1720-1733.

$\checkmark 45$ Whitwell JL, Sampson EL, Loy CT, Warren JE, Rossor MN, Fox NC, Warren JD: VBM signatures of abnormal eating behaviours in frontotemporal lobar degeneration. Neuroimage 2007;35:207-213.

46 Wright P, He G, Shapira NA, Goodman WK, Liu Y: Disgust and the insula: FMRI responses to pictures of mutilation and contamination. Neuroreport 2004;15:2347-2351.

47 Hodges JR: Frontotemporal dementia (Pick's disease): clinical features and assessment. Neurology 2001;56:S6-S10.

48 Snowden JS, Bathgate D, Varma A, Blackshaw A, Gibbons ZC, Neary D: Distinct behavioural profiles in frontotemporal dementia and semantic dementia. J Neurol Neurosurg Psychiatry 2001;70:323-332.

49 Frisoni GB, Laakso MP, Beltramello A, Geroldi $\mathrm{C}$, Bianchetti $\mathrm{A}$, Soininen $\mathrm{H}$, Trabucchi M: Hippocampal and entorhinal cortex atrophy in frontotemporal dementia and Alzheimer's disease. Neurology 1999;52:91100 .
50 Laakso MP, Frisoni GB, Kononen M, Mikkonen M, Beltramello A, Geroldi C, Bianchetti A, Trabucchi M, Soininen H, Aronen HJ: Hippocampus and entorhinal cortex in frontotemporal dementia and Alzheimer's disease: a morphometric MRI study. Biol Psychiatry 2000;47:1056-1063.

51 Van de Pol LA, Hensel A, van der Flier WM, Visser PJ, Pijnenburg YA, Barkhof F, Gertz HJ, Scheltens P: Hippocampal atrophy on MRI in frontotemporal lobar degeneration and Alzheimer's disease. J Neurol Neurosurg Psychiatry 2006;77:439-442.

52 Barnes J, Whitwell JL, Frost C, Josephs KA, Rossor M, Fox NC: Measurements of the amygdala and hippocampus in pathologically confirmed Alzheimer disease and frontotemporal lobar degeneration. Arch Neurol 2006;63:1434-1439.

53 Seeley WW, Crawford R, Rascovsky K, Kramer JH, Weiner M, Miller BL, GornoTempini ML: Frontal paralimbic network atrophy in very mild behavioral variant frontotemporal dementia. Arch Neurol 2008;65: 249-255.

$\checkmark 54$ Broe M, Hodges JR, Schofield E, Shepherd CE, Kril JJ, Halliday GM: Staging disease severity in pathologically confirmed cases of frontotemporal dementia. Neurology 2003; 60:1005-1011. 